\title{
sciendo
}

ISSN: $1231-4005$

e-ISSN: $2354-0133$

DOI: $10.2478 /$ kones-2019-0120

\section{OPERATIONAL VERIFICATION OF A SHIP MAIN POWER SYSTEM ELEMENT CHOICE - CASE STUDY}

\author{
Andrzej Adamkiewicz \\ Maritime Academy of Szczecin \\ Waty Chrobrego Street 1-2, 70-500 Szczecin, Poland \\ e-mail:a.adamkiewicz@am.szczecin.pl \\ Janusz Fydrych \\ Briese Bereederung Hamburg, Germany
}

\begin{abstract}
The article refers to results and conclusions on post-emergency repairs of a turbo-charging system of a DEUTZ engine of the SBV 8M 628 type of $1715 \mathrm{~kW}$ - the main power unit of a cement carrier. The failure of the turbocharger led to severing of a part of the exhaust outlet valve head. In order to determine the cause of the turbocharger fault, parametric identification of the reference state of the turbocharging system interacting with the ship main power engine has been carried out. The post-emergency servicing of the turbocharger comprised mounting a new blade rim of expansive instruments of smaller capacity than the so far used. Control measurement results of the power system after the replacement of the turbocharger turbine nozzle have been presented. Limitations of correct engine operation have been noted in the range of maximum load with continuous power (MCR). A range of corrective maintenance servicing of fuel equipment has been presented. Using the values of measured torque at the propeller shaft, incorrect interaction between the shaft and the main engine has been noted. A new propeller, adequate to the design operational parameters of the engine characteristics, has been chosen and mounted. The correctness of turbine expansive instrument replacement has been verified by correct interaction between the elements of the power system: propellermain engine - turbocharging system. Thus, a wider range of economically acceptable ship operation has been obtained.
\end{abstract}

Keywords: a ship main power system, turbo-charging system, operational parameters, main engine, ship propeller

\section{Introduction}

Ship operation is a multi-issue process taking into account interactions of the power system elements, machine sub-units and the environment in which the ship operates [4]. In the practice of a ship power system operation, interactions of these factors are responsible for reaching operational parameters which are different from the designed ones and in consequence maintenance of the vessel with a view to performing a transport task in accordance with design frames and functionality $[2,3]$.

Actual operational conditions of the main power system often enforce additional regulation services, replacement of a particular element of a sub-unit or a sub-system [11]. Such actions also enforce the ship owner's decisions leading to using equipment often outside the range of their nominal design operation [6,9]. It results from cargo availability, enforced deadline of the ship being ready for loading/unloading, which in consequence enforce ship owners' operational decisions. For the ship owners the decisive criterion of transport task completion is meeting the deadline and the economic factor of the transport service, not the rationality or economics of energy transformation and maintenance.

The realized strategy of the ship power system operation is disturbed by non-serviceability and random faults and failures of the elements of the main power system and of the auxiliary machines and equipment. It is possible statistically to observe characteristic kinds of faults and failures of 
ship engines [6, 9]. Fig. 1 presents the results of engine overload: partially burnt valve sockets in the main engine head and valve heads (authors' own photographs).
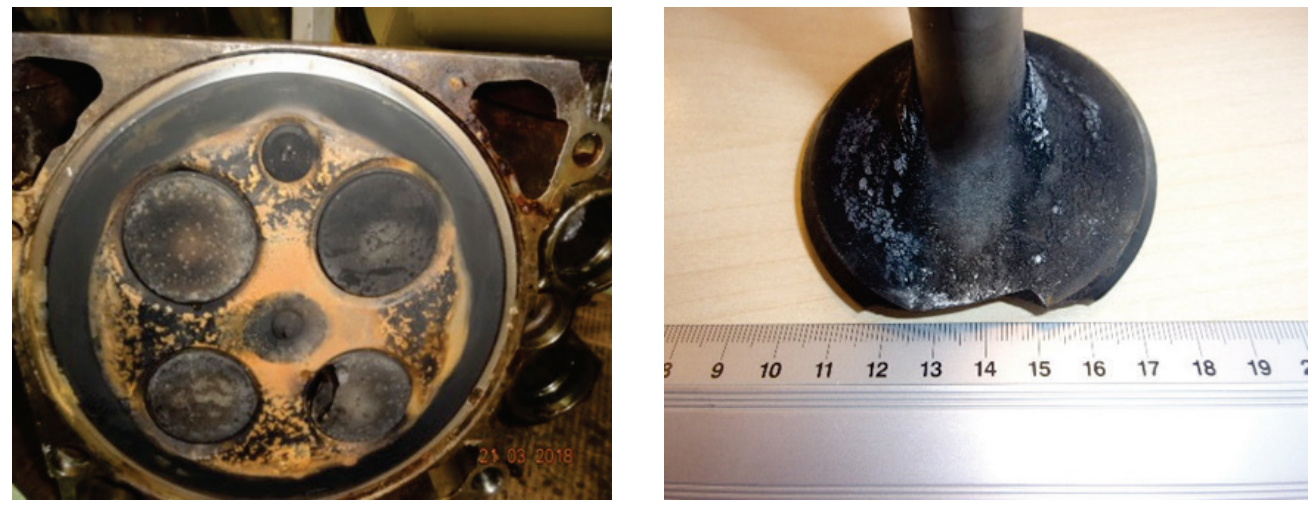

Fig. 1. View of partially burnt valve sockets in the engine cylinder head and valve heads

The most frequent faults and failures occur in the fuel system, tribological knots piston - rings - cylinder (PRC) and sub-units of the engine turbocharging system [9].

\section{Identification of the research object}

Technical condition of a coaster for carrying cement with 3716 DWT displacement was the study object generated by operational reality [13]. Cargo delivery was irregular and loading installation availability was restricted by certain dates, which enforced voyage speeds different from the designed ones and consequently energy states of the main power system. That availability has been determining the character of cement transport between ports, route length, ship speed and sailing time, which were the determiners of the transport task of the cement carrier.

\subsection{Main power engine}

The ship main power consisted of a non-reversible diesel engine of the 68M628 type manufactured by Deutz with nominal power of $1715 \mathrm{~kW}$, medium speed $\left(n_{\min }=250 \mathrm{rpm}\right.$; continuous operation $n_{\max }=1000 \mathrm{rpm}$ ) [7], supercharged by a turbocharger of the ABB VTR 254 type [1] interacting with a sequence gear driving a propeller with a constant pitch.

Change of direction of propeller rotation is performed throughout a gear unit and a clutch in the main gear with a transmission ratio ensuring the required rotational speeds of the propeller shaft for manoeuvring (350-850 rpm of the main engine SG) and sea voyage (1000 rpm of the main engine SG) in the following sequence of ship movement - rotational speeds of the main engine shaft: the propeller did not rotate at $n=350$ rotations/min of the main engine (SG).

At some manoeuvre settings of the fuel rail, the automatic control system increased the rotational speed of the engine shaft up to its design value and then turned on the propeller shaft in a set direction.

\subsection{Turbocharging system}

The main ship power in the charging system is equipped in a turbo-compressor of the $\mathrm{ABB}$ VTR 254 type, an engine with maximum rotational speed of 30,000 rpm, with mounted expansive instruments of a turbine (turbine nozzle) of the EF 21 type. The choice of turbine nozzle was made according to ship owner's requirements, for the main engine load corresponding to the load range of an engine with 850-900 rpm as its MRC (Maximum Continuous Rate). The correctness of choice of the elements of the turbocharging system was verified during shop sea tests, after general 
overhaul [10]. Fig. 2 shows shop test rotation characteristics of the engine turbocharging system with an EF21 type nozzle, whereas Figs. 3 and 4 show relations between state parameters: charging air pressure and outlet exhaust temperatures as a function of rotational speed of the main engine $[10,12]$.

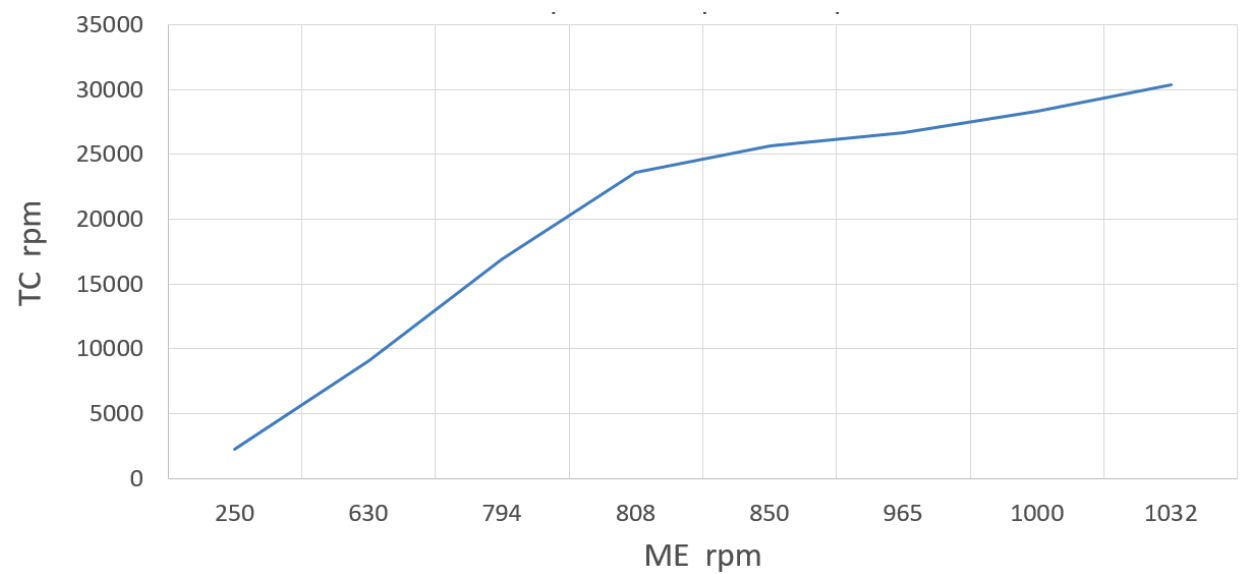

Fig. 2. Turbo-compressor rotational speed as a function of engine rotational speed-rotational characteristics of the turbocharging system

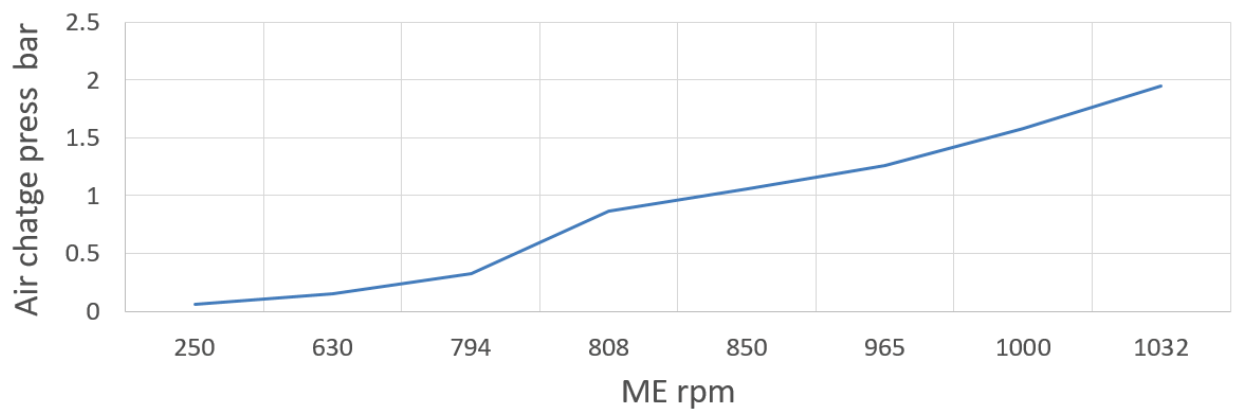

Fig. 3. Charging air pressure versus main engine rotational speed

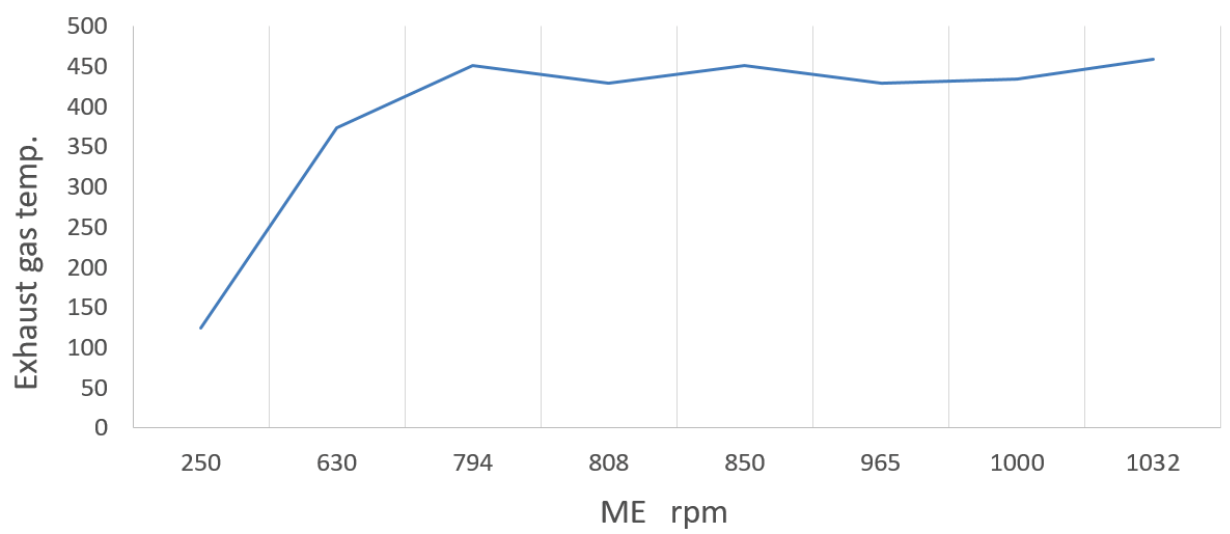

Fig. 4. Temperature of outlet exhaust gases versus main engine rotational speed

Choice of the turbo-compressor nozzle was made via an operational experiment. That was due to the ship's tight deadline regarding its come back to service on short distances between ports in the new sea area and consequently low sailing speeds, which favoured the ship owner's policy leading to minimizing fuel consumption $[10,11]$.

Figures 5 and 6 show operational parameters for the turbocharging, exhaust and air systems, with the EF 21 type turbine nozzles. The values of these parameters were close to design values of operational parameters of an engine charging system [7,9]. On their bases, technical services of 
the ship owner accepted those energy states of the engine as correct ones for operational speeds of the ship ensuring transport task performance in the so-far sailing conditions.

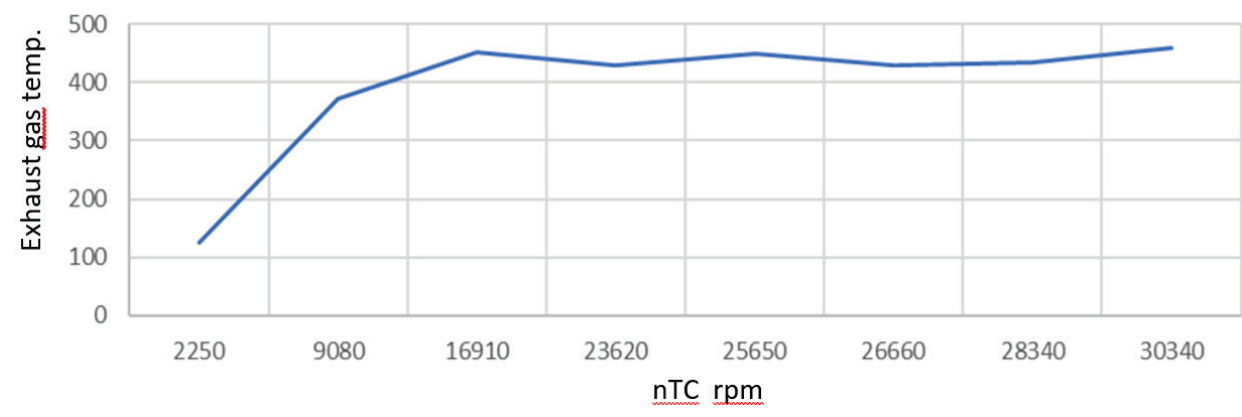

Fig. 5. Outlet exhaust temperature versus the rotational speed of the turbo-compressor

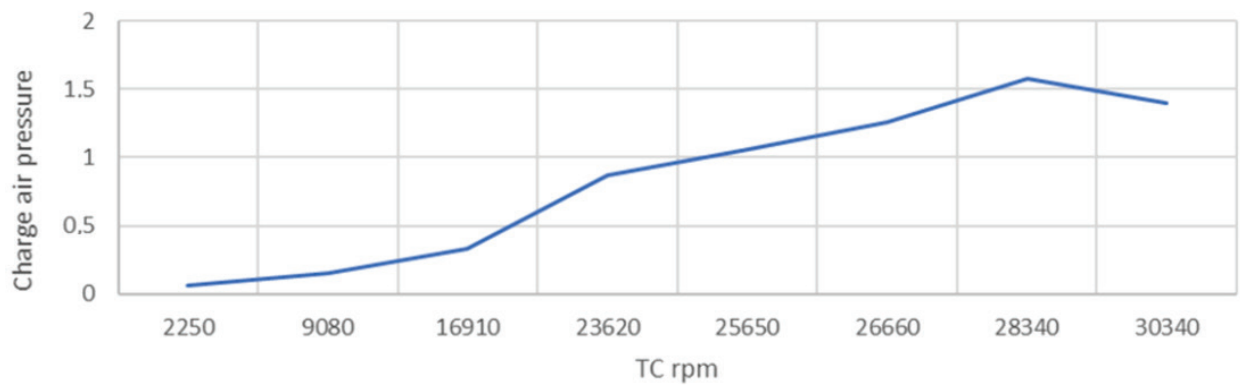

Fig. 6. Charging air pressure versus rotational speed of the turbo-compressor

The obtained runs of charging air pressure values and resulting from them outlet exhaust temperatures were in accordance with the manufacturers' requirements and they were accepted by the ship owner [7, 12]. For the ship speeds ensuring performance of the transport task, partial engine loads were sufficient.

\section{Consequences of changes in ship and main engine operational conditions}

After classification services and shop trials and after a short period of operation of the cement carrier, the ship owner changed the water region and character of the ship operation. Voyages at short distances could be performed at lower speeds obtained at the main engine load in the range of 0.6-0.7 of its nominal power. The voyages were short, lasting several hours and load rotation was different from previously. Working outside its designed operational range, the main engine was the subject of increased thermal and mechanical loads. In the new operational conditions of the main engine an increase of exhaust temperature was observed to the value of $480-500^{\circ} \mathrm{C}$, which is not acceptable for continuous engine operation. Multiple partial burns, cracks, and faults of valve heads in the cylinder head were observed. As a consequence, a failure in the turbocompressor turbine occurred. Fig. 7 shows a view of a crown of faulty guide blades and a rotor of a turbo compressor turbine.

New operational states required such speeds of the cement carriers, which could be supplied by its power system at $60 \%$ of nominal power load of the main engine with periodic load up to $90 \%$. The engine got into the range of insufficient operation $[1,6]$, pumping of the turbo-compressor occurred and as a result lack of charging air, the engine was temporarily overloaded and outlet exhaust temperatures increased leading to dynamically changing outside design range load states of the main power engine. Therefore, the temperatures of the outlet exhaust reached too high values, yet still acceptable, in the range of $450-480^{\circ} \mathrm{C}$. However, in the nominal power ranges of the main engine, the outlet exhaust temperatures exceeded limiting values reaching $480-520^{\circ} \mathrm{C}$. The new required range of the main engine power made continuous travel at full speed impossible 
and there was a need to use the main engine load corresponding to the rotational speeds of $800-850 \mathrm{rpm}$ for which the characteristics of a turbo-compressor, with the EF 21 type nozzle and ship owner's requirements corresponding to the previous sailing conditions, was chosen. At such reduced loads, the main power engine could function maintaining acceptable values of operational parameters.
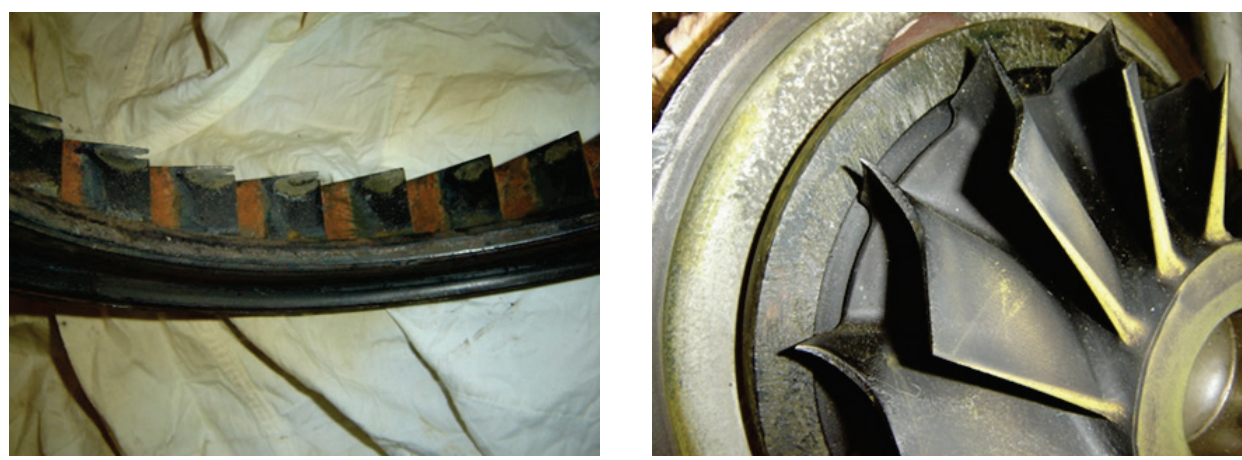

Fig. 7. View of faulty guide blades and the rotor of a turbo-compressor turbine

For the new ranges of load of the main engine, after consultations with the manufacturer $A B B$ Wartsilla, the EF 21 nozzle of the turbo-compressor was replaced by an EF 19 nozzle with smaller cross-sections of flow canals. As a result, the main power engine operated in a stable way, the temperatures of outlet exhaust decreased both at nominal sea travel as well as for its partial loads, which was verified by measurements performed when the ship was in operation. Figs. 8 and 9 present rotational characteristics of the turbocharging system [8].

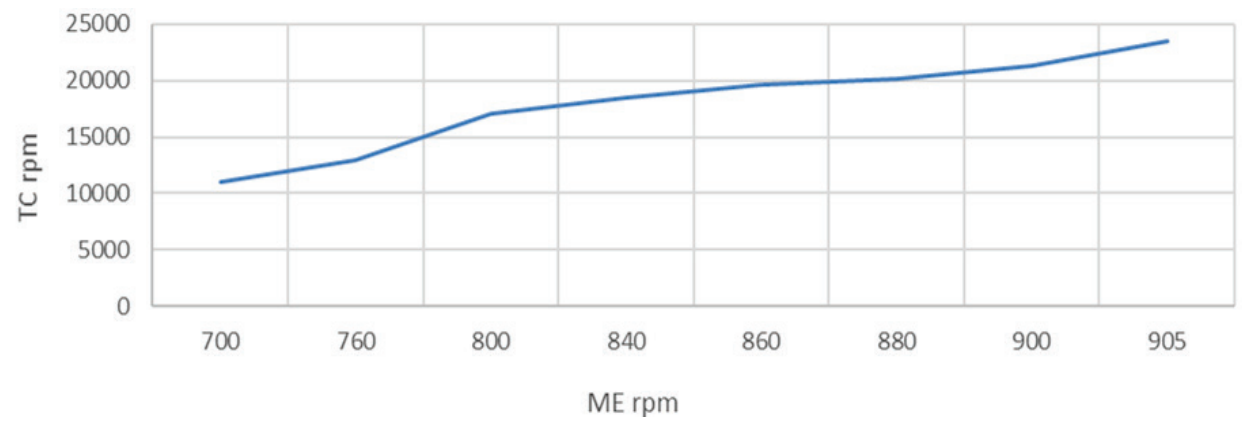

Fig. 8. Rotational speed of the turbo-compressor versus rotational speed of the main engine

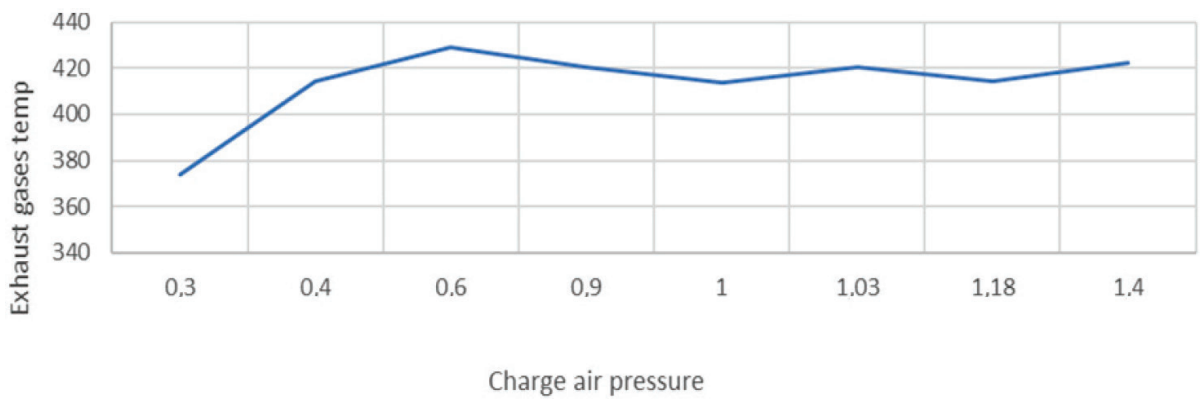

Fig. 9. Outlet exhaust temperature versus charging air pressure

New operational conditions of the main engine were accepted by technical services of the ship owner, however, still at the main engine load close to continuous power MCR, outlet exhaust temperature was higher than the design one [8].

As still the full installed power was not available, because of economic reasons of transport task performance, it was stated that the technical condition of the engine, on the basis of obtained 
operational parameters, was assumed to be sufficiently correct (partially worthy) and the ship was restored into liner traffic [8] to perform transport task and further studies on the main power system.

\section{Activities regulating the engine fuel system}

During ship operation on its route, the moment of fuel injection and the size of the supplied fuel doze were adjusted to the rotation angle of the crankshaft (using computer corrections of the rotation angle of the driving shaft of injection pumps). In order to do that, a corrector of injection pump setting was used.

Injectors were replaced, which together with simultaneous corrective servicing of injection pumps, decreased the outlet exhaust temperatures by approximately $10-20^{\circ} \mathrm{C}$ as well as the temperature of cooling water (outlet exhaust collectors are cooled by water from the main engine cycle) which still did not allow the main engine to function at its full power in a continuous way. Therefore, it was decided to adjust the fuel pump output to the safe load of the engine, which corresponded to 850-900 rpm. This fact, however visibly decreased operational speeds of the ship but enabled stable sailing at an increased continuous load, even with temporary overloads for example at averse hydrometeorological conditions (enabled the performance of a transport task). Fig. 10 shows the temperature of outlet exhaust versus the rotational speed of the main engine after corrective regulations to the fuel system.

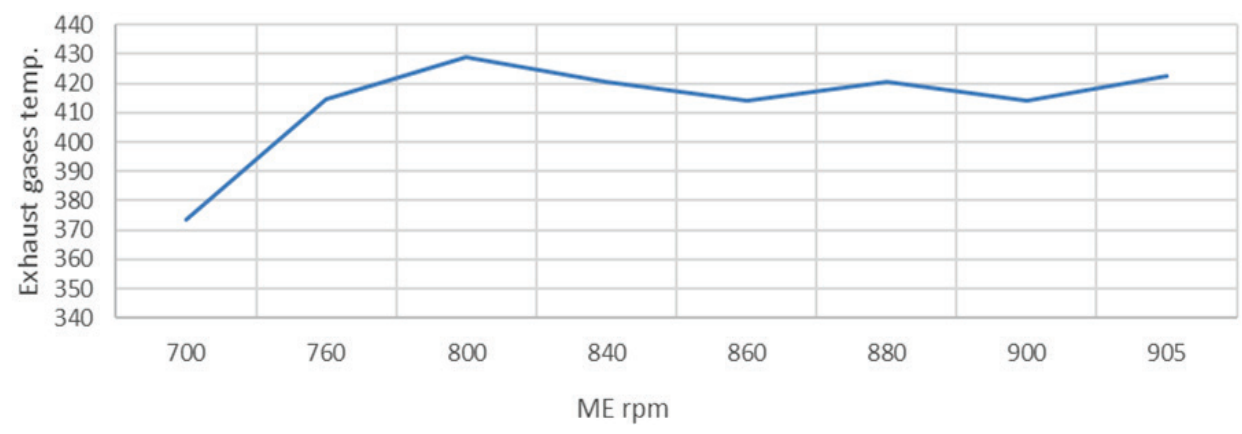

Fig. 10. The temperature of outlet exhaust gases versus the rotational speed of the main engine after corrective regulations to the fuel system

The presented results of corrective regulation services together with their operational effects were treated as operation of the main engine for the needs of the current transport task and they were accepted. Operational parameters of the engine and the ship's speed were sufficient for the ship owner's needs and the requirements of the performed function and the region of sailing as well as the required sailing speeds. Despite all the possible regulation activities that were undertaken, full installed power of the main engine was not reached [8].

\section{Analysis of efficiency of corrective services}

Replacement of the turbo-compressor turbine nozzle caused definite energetic effects. Tab. 1 comprises the values of measured parameters correlated to four definite rotational speeds of the main power engine as operational speed ranges. The results are given for both nozzles EF 21 and EF 19. The engine in the last option of transport task performance most frequently operated in the speed range from 800 to $850 \mathrm{rpm}$.

Replacing the EF21 nozzle with EF19, one resulted in reaching lower rotational speeds of the turbo-compressor and lower temperatures of exhaust gases. This tendency was maintained at $700-900 \mathrm{rpm}$ of the main engine, the temperature of the exhaust stabilized at $420^{\circ} \mathrm{C}$, which is approximately $30 \mathrm{~K}$ lower than when EP 21 nozzle was used. Rotational speed of the turbo- 
compressor decreased considerably, which did not lead to the decrease of charging air pressure, but simultaneously the exhaust temperature become lower. It limits the possibility of loading the engine to its full continuous power (MCR), for example at difficult sailing conditions [8].

Tab. 1. Listing of operational parameters of the engine and turbocharging system with EF 21 and EF 19 nozzles

\begin{tabular}{|l|c|c|c|c|c|c|c|c|}
\hline \multirow{2}{*}{$n_{\text {ME }}[\mathrm{rpm}]$} & \multicolumn{2}{|c|}{700} & \multicolumn{2}{|c|}{800} & \multicolumn{2}{c|}{850} & \multicolumn{2}{c|}{900} \\
\cline { 2 - 9 } & $\begin{array}{c}\text { Shop } \\
\text { test }\end{array}$ & $\begin{array}{c}\text { New } \\
\text { nozzle }\end{array}$ & $\begin{array}{c}\text { Shop } \\
\text { test }\end{array}$ & $\begin{array}{c}\text { New } \\
\text { nozzle }\end{array}$ & $\begin{array}{c}\text { Shop } \\
\text { test }\end{array}$ & $\begin{array}{c}\text { New } \\
\text { nozzle }\end{array}$ & $\begin{array}{c}\text { Shop } \\
\text { test }\end{array}$ & $\begin{array}{c}\text { New } \\
\text { nozzle }\end{array}$ \\
& EF 21 & EF 19 & EF 21 & EF 19 & EF 21 & EF 19 & EF 21 & EF 19 \\
\hline$n_{\text {T/C }}[\mathrm{rpm}]$ & 12543 & $\mathbf{1 1 0 0 0}$ & 19870 & $\mathbf{1 7 0 0 0}$ & 25690 & $\mathbf{1 9 0 5 0}$ & 26058 & $\mathbf{2 1 2 5 0}$ \\
\hline Charge Air press $[$ bar $]$ & 0.23 & $\mathbf{0 . 3}$ & 0.58 & $\mathbf{0 . 6}$ & 1.06 & $\mathbf{0 . 9}$ & 1.20 & $\mathbf{1 . 1 8}$ \\
\hline Exh. gas temp. $\left[{ }^{\circ} \mathrm{C}\right]$ & 405.8 & $\mathbf{3 7 3 . 7}$ & 440.8 & $\mathbf{4 2 8 . 8}$ & 450.8 & $\mathbf{4 1 6 . 9}$ & 440.8 & $\mathbf{4 1 4 . 3}$ \\
\hline
\end{tabular}

To increase the safety of the main engine operation, new outlet exhaust valves with higher thermal and mechanical resistance were mounted. Measurements (done with a torsiometer) of the power reached by the main engine showed that the engine was overloaded in the higher load ranges. Assuming that the regulation of the fuel equipment, media circulation, and automatic control of the main power were correct, the results of measurements indicated faulty characteristics of the applied ship propeller. Despite the introduced changes, it was not possible to get the engine to operate at its MRC; therefore, a decision to dock was made. Measurements of active surface of the propeller blades confirmed the previous conclusion that the propeller was too "heavy" in relation to the nominal power of the main power engine and its operational point was in the range of "heavy" operation of the ship drive. It was found out that the area of the pressure face of the propeller was $10 \%$ higher than the designed one and a new propeller recommended in the technical design for this type of engine was installed. Fig. 11 presents the characteristics of the new propeller.

The ship returned to further operation, which confirmed the correctness of replacing the propeller with the new one. The ship underwent long-term operational tests (travel with ballast, with cargo and in changeable hydro meteorological conditions). First sea trails after introducing the changes showed that the temperature of exhaust gases was up to $420^{\circ} \mathrm{C}$ at $920 \mathrm{rpm}$ of the main engine shaft and pumping was not observed in the turbo-compressor flow canals both at manoeuvring and within full load range at stable sea travel [5].

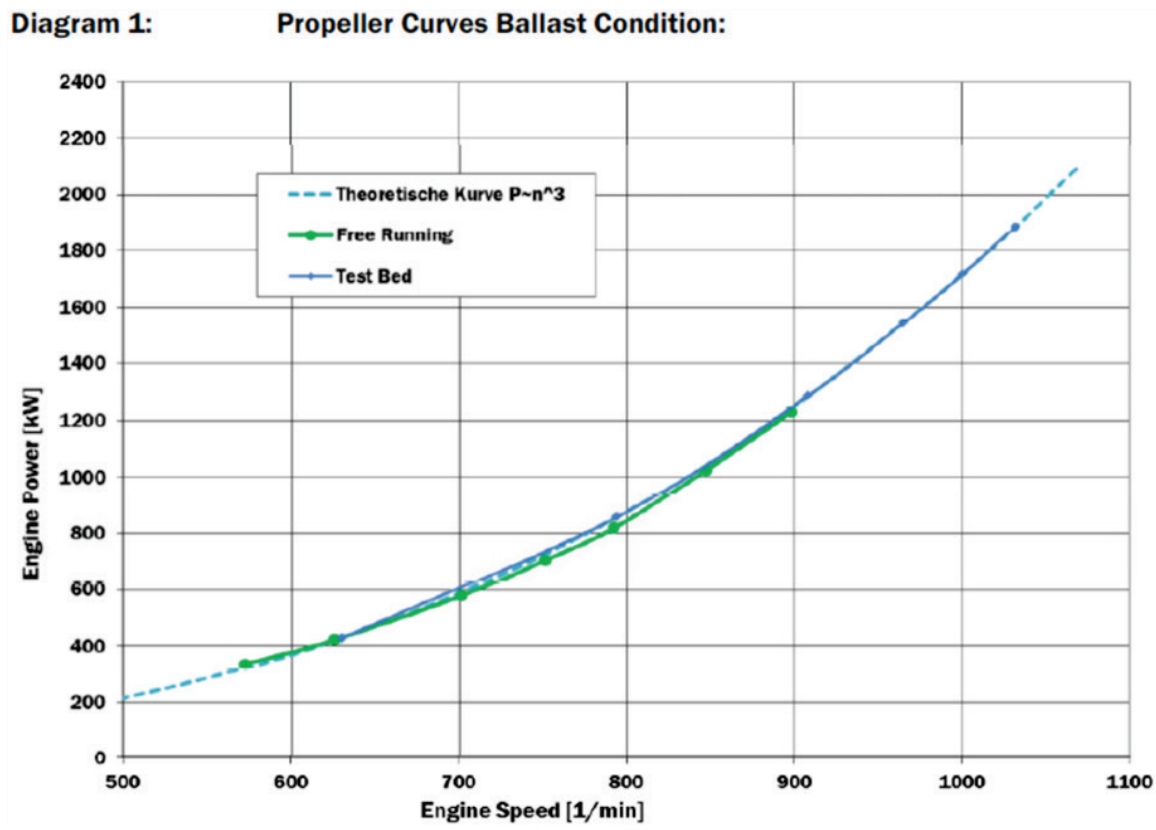

Fig. 11. Characteristics of a new propeller for different options of sailing, free running and sea travel [10] 


\section{Conclusions}

As a result of undertaken actions the range of possible maximum loads of the main engine was limited from the upper side to the values ensuring safe operation determined by the speed limit of $\mathrm{pm}$. Due to the fact that during most of the sailing time, the ship main power system operates at partial and low load ranges, therefore it can be stated that replacing the EF 21 turbo-compressor nozzle with the EF 19 one was rational for that way of main power system operation. Installation of a new propeller in accordance to design specifications resulted in the improvement of the main ship power system operation.

The carried out research showed that the corrective services of the technical and energy condition of the main power engine (here replacement of the turbo-compressor turbine nozzle) in relation to the change of ship operational conditions, ship owner's needs together with the correction of fuel equipment settings and measuring the real load of the main power engine in confrontation with the design operational point is a means to perform a transport task in different new conditions resulting form of long-term transport contracts.

\section{References}

[1] ABB Turbo V VTR 254 HT 3881 turbo-compressors - manual.

[2] Adamkiewicz, A., An Analysis of Cause and Effect Relations in Diagnostic Relationships of Marine Diesel Engine Turbochargers, Scientific Papers of the Maritime University of Szczecin, 31 (103), pp. 5-13, 2012.

[3] Adamkiewicz, A., Michalec, G., General Diagnostic Model of a Marine Diesel Engine. Turbocharger, Marine Technology Transaction, Polish Academy of Sciences Publisher, Vol. 11, pp. 25-40, Gdansk 2000.

[4] Adamkiewicz, A., Michalski, R., Zeńczak, W., Chosen Technological Problems of Energy Conversion in Ship Power Systems (in Polish), Publisher Kaprint, Lublin 2012.

[5] C/Eng daily rep. - Brise form of Main Engine condition.

[6] House, L., Hill, J., Pounders Marine Diesel Engine and Gas Turbines, Ninth Edition, Oxford 2009.

[7] Main power engine of the DEUTZ SBV 628 type manual, 2001.

[8] Operational reports of the Chief Mechanic after the replacement of the turbo-compressor turbine nozzle with the EF 19 nozzle.

[9] Piaseczny, L., Technology of Repairs of Diesel Ship Engines, Maritime Publishing House, Gdansk 1992.

[10] Report on the ship main power engine after a sea trial Shaft Power Measurements "...", Report $\mathrm{m}+\mathrm{m}$ schlott 2017.007, Ingenieurbüro $\mathrm{m}+\mathrm{m}$ schlott Engineering Consultancy, 2007.

[11] Ship Owner's Technical Bulletin - Brise - Tech/Dept., September 2018.

[12] Turbocharger Efficiencies - Definitions and Guidelines for Measurement and Calculation, The International Council on Combustion Engines, 2007.

[13] Wajand, J., Wajand, J., Medium - and High-Speed Piston Diesel Engines, Publishing House, Scientific and Technical, Warsaw 2005.

Manuscript received 24 August 2019; approved for printing 16 December 2019 